\title{
Interventricular septal cleft aneurysm
}

\author{
Negareh Mousavi MD MHSc FRCPC ${ }^{1}$, James Tam MD FRCPC ${ }^{1}$, lain Kirkpatrick MD FRCPC ${ }^{2}$, \\ Davinder S Jassal MD FRCPC ${ }^{1,2,3}$
}

\begin{abstract}
A
57-year-old man with a history significant for a bicuspid aortic valve and repaired coarctation of the aorta at 10 years of age, underwent transthoracic echocardiography for routine follow-up. Transthoracic echocardiography revealed a bicuspid aortic valve with a moderate degree of aortic regurgitation. A cleft aneurysm (arrow) was incidentally noted in the midinterventricular septal region on the left ventricular (LV) side, measuring $11 \mathrm{~mm} \times 5 \mathrm{~mm}$ (Figure 1A and Video 1A). There was no flow across the defect on colour Doppler imaging to suggest a ventricular septal defect. Cardiac magnetic resonance imaging confirmed the presence of a focal cleft (arrow) within the midventricular septum on the LV side, extending over a length of $8 \mathrm{~mm}$ and to a depth of $7 \mathrm{~mm}$ (Figure 1B and Video 1B).
\end{abstract}

Aneurysms of the muscular interventricular septum are a distinct entity with a poorly defined etiology and clinical course. Acquired causes secondary to coronary artery disease, coronary anomalies, trauma, infections, cardiac surgery and Kawasaki disease have been described. In the absence of a readily identifiable acquired etiology, idiopathic septal cleft aneurysms are believed to be congenital. There was no evidence of delayed enhancement of the LV myocardium on cardiac magnetic resonance imaging to suggest an ischemic etiology of the cleft aneurysm. Potential cardiac complications include rupture, cardiac arrhythmias, congestive heart failure and thromboembolism. Although management is generally conservative, as in the present patient, surgical excision with repair is recommended in high-risk or symptomatic patients.

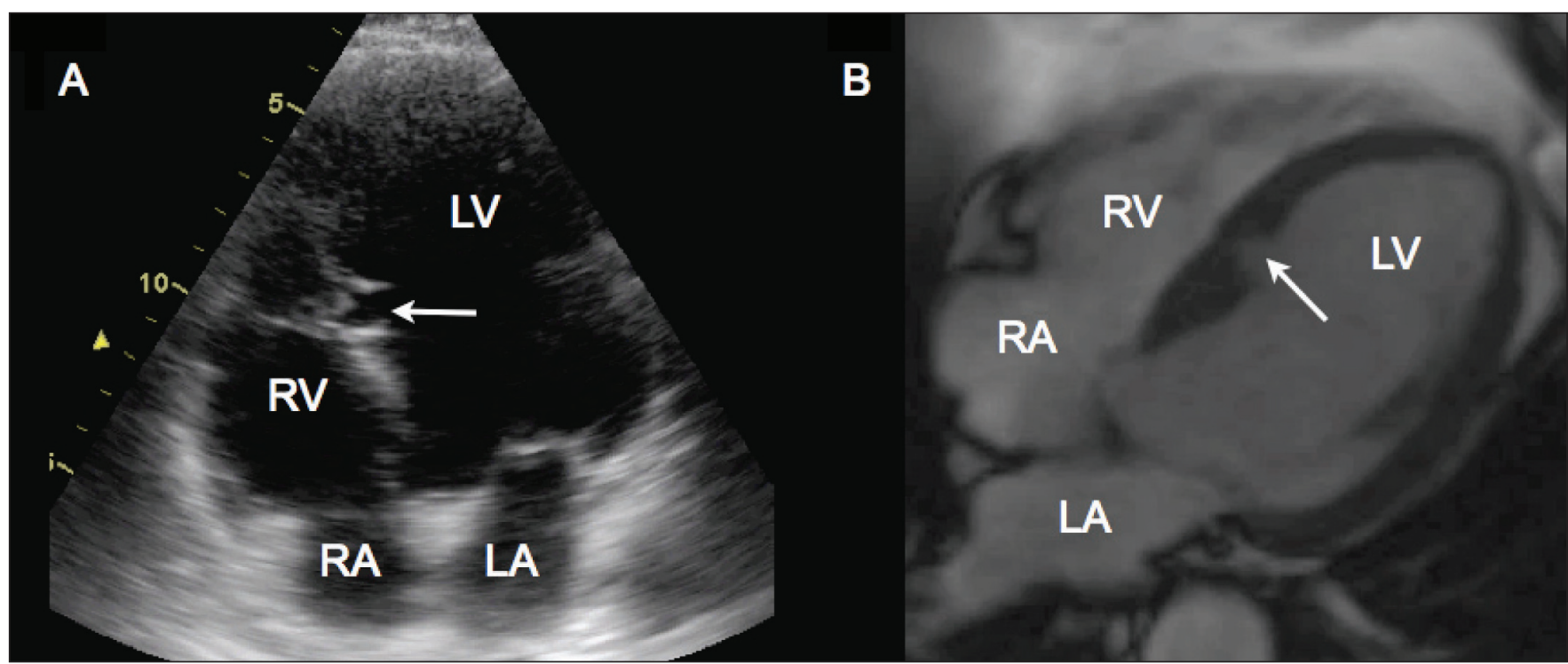

Figure 1) LA Left atrium; LV Left ventricle; RA Right atrium; RV Right ventricle

${ }^{1}$ Section of Cardiology, Department of Cardiac Sciences; ${ }^{2}$ Department of Radiology; ${ }^{3}$ Institute of Cardiovascular Sciences, St Boniface Research Centre, University of Manitoba, Winnipeg, Manitoba

Correspondence: Dr Davinder S Jassal, Bergen Cardiac Care Centre, Cardiology Division, Room Y3010, Department of Cardiac Sciences, St Boniface

General Hospital, 409 Tache Avenue, Winnipeg, Manitoba R2H 2A6. Telephone 204-237-2023, fax 204-233-2157, e-mail djassal@sbgh.mb.ca

Received for publication October 14, 2008. Accepted October 19, 2008 